\title{
Ventricular Tachycardia, CTCAE 5.0
}

National Cancer Institute

\section{Source}

National Cancer Institute. Ventricular Tachycardia, CT CAE 5.0. NCI Thesaurus. Code C146733.

A disorder characterized by a dysrhythmia with a heart rate greater than 100 beats per minute that originates distal to the bundle of $\mathrm{His}$. 